\title{
Energy values of feeds for livestock and their prediction
}

\author{
A. J. H. van Es
}

Institute for Livestock Feeding and Nutrition Research (IVVO), Lelystad and Dept. of Animal Physiology, Agricultural University, Wageningen, Netherlands

\begin{abstract}
A survey is given of the development of methods for practical application to predict a feed's energy value for livestock in the Netherlands. Predictions based on chemical composition were developed first but are now being replaced by methods using enzymes and/or near-infrared reflection techniques.
\end{abstract}

\section{Relationships between energy value of feeds and their content of digestible nutrients}

The basic studies of Kellner (1905) in Germany and Armsby (1917) in the USA around 1900 on energy metabolism of livestock drew also in the Netherlands immediate attention. Soon afterwards the Department of Animal Physiology of the Agricultural University at Wageningen bought part of the equipment needed for such studies. However, due to the two World Wars and the economical crisis between those as well as due to growing interest in vitamin, mineral and protein metabolism of animal and man it lasted until 1958 before in the Netherlands calorimetric studies with large animals were done on a large scale. At present the country has several chambers for indirect calorimetry, four at Wageningen and four at Lelystad, for cattle, sheep and pigs, two at Wageningen and two at Maastricht for humans and a few at Wageningen, Beekbergen and Utrecht for poultry. The chambers for humans at Wageningen had been used earlier for livestock. Because of the increased interest in man's energy metabolism and the similarity in equipment needed, two cattle chambers were converted into small hotel rooms for human use in 1980 and used for studies on the effect of feeding level and on obesity with financial support of the Netherland Heart Foundation (van Es et al., 1984; de Boer, 1985).

Already from the early work of Kellner and Armsby it became clear that for a good understanding of an animal's energy metabolism it is of foremost importance to know to which extent the animals digest the various feeds. Their energy feed evaluation systems, the starch equivalent and therm systems, used the digestible nutrients of the feeds as the starting point. Because of these and other considerations already in 1915 the State Agricultural Experiment Station (at that time at Hoorn, later renamed in Institute for Livestock Feeding and Nutrition Research (IVVO) and since 1975 at Lelystad) performed a few digestibility trials of feeds with pigs. In 1932 a large series of such studies began (Dijkstra, 1954), first with bulls but soon afterwards with sheep because these animals digest feedstuffs to the 
same extent as mature, non-producing cattle and are easier and cheaper experimental animals. In 1955 digestibility studies with pigs were taken up again on a large scale and in the 1960s and 1970s also many digestion studies with veal calves and dairy cows were performed, both at Wageningen, Hoorn and Lelystad.

\section{New energy systems for livestock, based on digestible nutrients}

The renewed interest in the 1950s in energy metabolism of livestock led to a series of EAAP Symposia on energy metabolism of farm animals with participation of all major teams engaged in such research in the world. The first Symposium was held at Copenhagen in 1957, the tenth at Airlie, USA, and the next is to be organized in the Netherlands in 1988 as was the case in 1961 with the second Symposium.

As a result of all these activities on energy metabolism in many countries and also in the Netherlands the old systems of evaluation of the energy values of feeds and of energy requirements of animals (starch equivalent, total digestible nutrients, therms) were replaced by new systems (net energy fattening, net energy lactation, metabolizable energy). The Netherlands made efforts to keep the total number of such systems low but these were only partially successful (van Es et al., 1978; van Es \& Schiemann, 1986). This was mainly caused by local differences in feeds used, in ways livestock were fed and in available information on these feeds.

The calorimetric studies with cattle at Wageningen and Lelystad and with pigs at Lelystad confirmed that indeed the contents of digestible nutrients of feeds are the main determinants of their energy value for those animals. Similar results were obtained in such studies in other countries. All the new and old systems have as their base the contents of digestible nutrients, the digestible energy (DE) or the metabolizable energy (ME, equal to the gross energy of the feed minus energy in faeces, urine and $\left.\mathrm{CH}_{4}\right)$. DE and $\mathrm{ME}$ values can be derived from digestible nutrients with little error.

Thus, for the application of the new systems in practical animal husbandry it was important that information on digestibility of the various feeds could be easily obtained. Cheap, reliable prediction methods became in great demand, especially in the Netherlands where after 1960 the number of feedstuffs used for livestock increased considerably. Many new feedstuffs from overseas and by-products from food industry became available at a low price. Often little was known about their contents of digestible nutrients and usually they showed from batch to batch more variability in these contents than the feedstuffs used so far. Furthermore pasture utilization was intensified by high fertilizer application and forage conservation changed from making of hay and high-moisture silage to ensiling after a few days' wilting; artificial drying is applied also. Also, the use of maize silage as a feed increased more than tenfold since 1960.

\section{The prediction of a feed's content of digestible nutrients from chemical composition}

In principle it is not difficult to perform a digestibility trial of feedstuffs with animals, i.e. an in vivo trial. The result is highly accurate when performed correctly. 
The feed has to be fed to the animals, preferably to three or four, for two to four weeks - longest for ruminants - in precisely weighed daily quantities. Representative samples of the feed, of any refusals (also weighed precisely) and of the faeces collected (and weighed) during the last seven to fourteen days have to be analysed for dry matter, ash, crude protein, crude fat, crude fibre (or neutral and acid detergent fibre and lignin) and, usually, energy (by bomb calorimetry). However, the duration of the trial and the amount of work needed for caring for the animals, also during weekends, and of analysis make such in vivo trials slow and very expensive.

For these reasons already in the 1930s Brouwer \& Dijkstra (see Dijkstra, 1954) tried to find methods to predict digestibilities rather than to measure these with animals. From the results of their digestion trials with sheep they derived relationships between the content of digestible organic matter (DOM) and digestible protein (DP) of fresh grass and preserved forages and their chemical composition. After the Second World War this and subsequent work resulted in a manual for the prediction of the feeding value of roughages (Working group, 1958). The DP content was used as the protein feeding value. The conversion of DOM contents into an energy feeding value was mainly a matter of a few calculations.

In the 1970s similar relationships were derived for some concentrate feedstuffs showing variable composition. These were published in the Veevoedertabel, the Dutch feeding table, together with chemical composition, digestibilities and feeding values of the other concentrate feedstuffs (CVB, 1957). Two committees are regularly updating the 'Manual' and 'Veevoedertabel' which are in general use by most farmers, feed manufacturers and extension officers in the Netherlands and part of Belgium. Recently the old and new data are being stored in a computer data bank for facilitating calculations and updating, and for making type-written surveys.

\section{Prediction of the content of digestible organic matter of feeds by enzymatic and by plant cell partitioning methods}

In most of the equations used for predicting DOM the content of crude fibre was used as the criterion. Criticism on crude fibre from scientific sides was heard at regular intervals from the development of this analysis more than 100 years ago onwards. The determination is empirical and requires quite a bit of attention for maintaining a reasonable degree of reproducibility. It does not very well partition the sample in digestible and indigestible components, certainly not for ruminants. This was the intention of those who originally developed the method. Part of the indigestible lignin dissolves and so is not found in the residue, the crude fibre; moreover the ruminant can digest a considerable part of the hemicellulose and cellulose of crude fibre (for monogastric animals these two components are indigestible or nearly so). Thus it is understandable that in the 1960 s two new approaches to predict digestibility of forages for ruminants in a more scientific way received much attention. The first consisted of incubating a sample anaerobically for 48 hours with rumen fluid at $38^{\circ} \mathrm{C}$ followed by a treatment with pepsin at low pH also at $38^{\circ} \mathrm{C}$, 
clearly an attempt to imitate a ruminant's digestion in vitro (Tilley \& Terry, 1963). Any organic matter not recovered in the residue was considered digestible. The second method, proposed by Van Soest (1985), was an attempt to partition the sample of plant material by treatment with neutral detergent (ND) in cell content, a highly digestible fraction, and in cell wall. In a second step by further treatments the contents of acid detergent fibre (ADF) and acid detergent lignin (ADL) are measured; the ADL content correlates fairly well with the digestibility of the cell wall.

\section{Predictions of DOM of feed for ruminants by incubation with enzymes}

Soon after its development by Tilley \& Terry the in vitro method with rumen fluid and pepsin was tested in the Netherlands (van der Koelen \& van Es, 1973) and improved. Some years later a technique was found that improved the accuracy of the prediction of the DOM content with this in vitro method. It proved to be essential to include in the in vitro run some samples with known in vivo DOM content of similar type as the unknown samples. In fact, the in vitro procedure is a fairly coarse imitation of the in vivo digestion process but including some in vivo samples permits to correct for most errors caused by the poor imitation.

Since 1980 this method is available in the Netherlands also for routine analysis of forage samples from practice (it is used for some 100 samples per year). Furthermore the method has been adapted for use for concentrate feeds.

A disadvantage of the in vitro method of Tilley \& Terry is that it requires a regular supply of rumen fluid. That is the reason that at Lelystad and elsewhere the replacement is being studied of rumen fluid by mixtures of industrially available enzymes, cellulases and hemicellulases. For roughages this was found possible provided that in the same in vitro run of unknown samples some samples with known in vivo DOM content of comparable material were included. These samples have to be selected with still more care than for the method that used rumen fluid. Also for most concentrate feeds this modification of the method can be used. For some types, however, such as those with higher fat contents, there are still difficulties. These might be solved by prior extraction of most of the fat and/or removal of starch with an enzyme. It is expected that this in vitro method for predicting a feed's DOM with industrially available enzymes can be applied for nearly all single feeds and mixed feeds in the near future (van der Meer \& van Es, in press).

\section{Predictions of DOM of feeds for ruminants with detergents}

The method of Van Soest received initially much attention because it partitioned plant material in a much more acceptable way than the crude fibre analysis. While applying the method for routine purposes, for example in the USA, usually against the advice of Van Soest - the not very pleasant and not too precise determination of ADL was omitted. A ring test of the European Community, organized by IVVO at Lelystad, indeed showed that Van Soest's method without ADL did not predict the DOM content of forages any better than the crude fibre method. This study also showed that repeatabilities and reproducibilities of lignin determinations, ADL included, were poor. 
Predictions of DOM of feeds for pigs

As said above the residue after treatment of a sample with neutral detergent (NDF) is hardly digestible for pigs so that the difference between organic matter (OM) and NDF for many feeds informs fairly well on the DOM content. Feeds for pigs, however, often contain a lot of starch that might make the NDF determination less precise. This was one of the reasons for searching for other prediction methods. Three of those can be found in the literature. The first method uses in vitro incubation with fluid from the small intestine of a pig collected through a cannula. The second method uses small samples contained in a nylon bag (pore size $40 \mu \mathrm{m}$ ) introduced in the duodenum through a cannula and recovered from the faeces; any organic matter that disappears is considered to be DOM (in sacco method). The third method imitates the digestion process by incubating the feed samples with industrially available enzymes.

Method two and three drew most attention at Lelystad (Metz \& van der Meer, in press) and are being studied intensively. Both have the advantage that the DOM content of single feedstuffs can be studied separately. In an in vivo digestion trial this is often not possible: the animals do not want to eat enough of it and such a single feed might be deficient as to protein, vitamins or minerals. In such a case two in vivo trials have to be done, one with a basal ration and one with a mixture of feed under test and the basal ration. Not only this procedure does give twice as much work but it also lowers the precision of the result for the feed under test because of the dilution with the basal ration.

\section{A new prediction technique based on physical properties of feeds}

During the 1970s a completely new method for analysing feeds (and other materials) was developed. It is based on absorption and reflection of near-infrared light (NIR) measured by spectrophotometer. A bundle of near-infrared light with wavelengths between 1100 and $2500 \mathrm{~nm}$ is thrown on the sample. Due to the composition of the sample at various wavelengths some of the light will be absorbed. The reflected light therefore informs on the composition of the sample.

Absorptions of near-infrared light are caused by various organic molecular groups and water of the sample. They are seldom sharply located at a few wavelengths or narrow wavelength bands. The correct interpretation of the reflection spectrum is therefore rather difficult. Usually it is done in an empirical way by comparing the spectrum of the test sample with spectra of many samples of similar material of which the property of interest has been determined with conventional procedures (see e.g. Honigs, 1985). For chemical properties these procedures are the chemical analyses. For properties such as the DOM content these consist of in vivo digestion trials or in vitro ones in which case the actual results have been corrected to the in vivo situation by inclusion of some in vivo samples in the same in vitro run as explained above.

The NIR method is very rapid (less than two minutes), non-destructive and does not use any chemicals. However, the apparatus is expensive and much work has to be done as described above before a prediction equation is found that is sufficiently 
precise and 'robust', i.e. nearly insensitive to possible abnormalities of the sample. Moreover, a regular check with samples, analysed conventionally, is needed to maintain high prediction precision, especially in case of samples from a new harvest, another region, etc.

At present three types of NIR device are available: a very expensive one that scans the whole region of $1100-2500 \mathrm{~nm}$, a cheaper one that measures only at a small number of wavelengths by using filters, and a mixture of these, the tilting filter apparatus.

Filter devices are already for some years being used in feed industry with great success for measuring the chemical composition (protein, fat, water) of a number of concentrate feedstuffs, i.e. raw materials, having variable composition from batch to batch. The derivation of the necessary prediction equations was developed by the feed industry itself; most of the work needed consisted of collecting a large number of samples of each feed showing sufficient variation in composition and analysed conventionally. For other properties of concentrate feeds for which the absorptions in the NIR region are less well-defined it can be expected that first scanning instruments have to be used to find those wavelengths that predict best. Then filters of these wavelengths can be installed in a filter apparatus or chosen when a tilting filter one is used.

Scanning devices have been used for predictions in forages in the USA, Belgium, England, the Netherlands and some other countries in Europe. In most cases the aim was to predict the chemical composition, and among this the crude fibre content for the calculation of DOM with conventional regression procedures. In fact, such a two-step prediction is not a very logical choice when compared with a direct prediction by NIR spectroscopy of the DOM content, the more so because the relationship in forages between crude fibre and DOM content is not very strong. The first four countries mentioned above also perform the direct prediction of DOM content of forages with good or reasonable precision (Shenk \& Westerhaus, in press; Biston et al., 1985; Murray, 1985; van Es et al., in press).

\section{Near-infrared procedures for routine application in the near future for forages in the Netherlands}

In the Netherlands preparations are being made to replace the routine prediction of protein and DOM content of forages for ruminants based on chemical analysis (crude protein, crude fibre, ash) by the NIR technique with, for DOM content, the direct approach. It concerns soms 100000 samples from farmers per year. The best method of deriving accurate and 'robust' prediction equations would be to collect and measure for each type of forage large numbers of samples showing great variability and with known chemical composition and in vivo DOM content. This requires far too much time and work. An acceptable alternative is using samples analysed for DOM content by in vitro methods with industrial enzymes, having carefully selected samples with known in vivo DOM content in each run. This procedure also permits the routine laboratories to do the necessary regular checks of the NIR predictions themselves. Much work on the development of methods for routine ap- 
plication of the NIR was done at Lelystad and with regard to maize silage nears its completion. The results will be offered to the two routine laboratories that analyse samples from the farmers.

The European Community showed interest in this kind of prediction of feeding value by near-infrared techniques and assisted by giving the opportunity to hold a workshop at the end of 1985 in Brussels. It was attended by most groups of EC member countries working in this field. During this workshop a ring test was planned, to be organized by the Federal Republic of Germany and the Netherlands, on the prediction of chemical composition and DOM content of forages with the NIR technique.

\section{References}

Armsby, H. P., 1917. The nutrition of farm animals. Macmillan, New York, 743 pp.

Boer, J. O. de, 1985. Energy requirements of lean and overweight women, assessed by indirect calorimetry. Thesis, Wageningen, $118 \mathrm{pp}$.

Biston, R., P. Dardenne \& C. Demarquilly, 1985. Prediction of forage in vivo and in vitro digestibility by NIRS. CEC Seminar on forage digestibility by NIRS (Brussels, 3-4 December 1985).

CVB (Centraal Veevoederbureau in Nederland), 1957. Veevoedertabel. Revised in 1967, 1970, 1977 and 1983. CVB, Lelystad, Netherlands.

Dijkstra, N. D., 1954. What has the State Agricultural Experiment Station at Hoorn contributed to research into the feeding value of roughage? Netherlands Journal of Agricultural Science 2: 273-297.

Es, A. J. H. van, M. Vermorel \& H. Bickel, 1978. Feed evaluation for ruminants: New energy systems in the Netherlands, France and Switzerland; general information. Livestock Production Science 5: 327-330.

Es, A. J. H. van et al., 1984. Human energy metabolism below, near and above equilibrium. British Journal of Nutrition 52: 429-442.

Es, A. J. H. van \& R. Schiemann, 1986. Systems of calculating energy values of feeds and energy requirements of dairy cattle: comparison of the new proposals. Bulletin International Dairy Federation 196/1986: 54-58.

Es, A. J. H. van, J. H. Wolsink \& H. W. Vedder (in press). Experiences with the InfraAlyzer 500 for predicting the digestibility of forages. Proceedings NIR-users seminar (FAL, Braunschweig, 1-2 Oct. 1985).

Honigs, D. E., 1985. Near infrared analysis. Analytical instrumentation 14: 1-62.

Kellner, O., 1905. Die Ernährung der landwirtschaftlichen Nutztiere. Parey, Berlin, 594 pp.

Koelen, C. J. van der \& A. J. H. van Es, 1973. A comparison of some laboratory techniques for the estimation of the digestibility of the organic matter in forage samples. Netherlands Journal of Agricultural Science 21: 199-205.

Meer, J. M. van der \& A. J. H. van Es (in press). Optimal degradation of lignocellulosic feeds by ruminants and in vitro digestibility tests. Proceedings COST-84 Workshop (Lelystad, March 1986).

Metz, S. H. M. \& J. M. van der Meer (in press). Nylon bag and in vitro techniques to predict in vivo digestibility of organic matter in feedstuffs for pigs. Proceedings 3rd International Seminar 'Digestive physiology in the pig' (Copenhagen, 15-18 May 1985).

Murray, I., 1985. NIR measurement of nitrogen and digestibility in grass and silage. CEC Seminar on forage digestibility by NIRS (Brussels, 3-4 December 1985).

Shenk, J. S. \& M. O. Westerhaus (in press). Recent U.S. developments in NIRS hardware and software. Proceedings NIR-users seminar (FAL, Braunschweig, 1-2 Oct. 1985).

Tilley, J. M. A. \& R. A. Terry, 1963. A two-stage technique for the in vitro digestion of forage crops. Journal of the British Grassland Society 18: 104-111. 


\section{A. J. H. VAN ES}

Van Soest, P. J., 1985. Definition of fibre in animal feeds. In: W. Haresign \& D. J. A. Cole (Eds.), Recent Advances on Animal Nutrition 1985, p. 55-70. Butterworths, London.

Working group, 1958. Manual for the calculation of the nutritive value of roughages. Revised in 1965 and 1977. CVB, Wageningen. 